exceptions to this rule, and understanding them has proved to be a challenge for evolutionary biologists.

These exceptions form the centre of gravity of Sex Wars. Michael Majerus of the University of Cambridge starts off by walking us through the background and some of the basics: asexual versus sexual reproduction, sexual selection, the sex-determining mechanisms, the sex ratio and the various 'economic' factors that can lead to uneven sex ratios are all covered in the opening sections. But the bulk of the book is about the various genetic conflicts that knock the sex ratio off its evolutionary equilibrium.

For a gene located on a nuclear autosome - any chromosome except the sex chromosomes - life is as good in a male as it is in a female, in terms of the probability of being transmitted to the next generation. For extranuclear genes, however, males are a genetic dead-end because the sperm contributes nothing but its nuclear genes to the fertilized zygote. Cytoplasmic genes located in mitochondria or in endocellular microorganisms are expected to favour the female line, through which they are transmitted to the next generation.

This sets the stage for a battle between autosomal genes on one hand, and genes with unequal transmission rates in the two sexes on the other. I found the portrayal of these opponents by Majerus very exciting, and his account of them offers many insights. These evolutionary law-breakers use a variety of intrusive tactics (including killing sperm containing Y chromosomes, transforming genetic males into functional females, or simply killing males), which all bias the sex ratio towards females, sometimes even to the point when the 'host' is driven close to the brink of extinction because of a lack of males in the population. The autosomal genes fight back, however. Majerus describes several cases of autosomal 'rescue' genes that counter the effects of the lawbreakers. The natural history of sex-ratio distortion is the definite strong point of this book - Majerus tells many intriguing and entertaining tales about various reproductive curiosities.

No book can be written for everyone, but every book should be written for someone. This book is aimed at "a wide audience". Any reader of this book will find much of interest, but will also be frustrated. Like the indecisive Buridan's ass who could not choose between two equal bales of hay and therefore starved to death, Majerus roams the treacherous no-man's-land that lies between the general reader and the specialist, unable to quite reach either. General readers will stumble over many of the terms and turns in the more detailed and complicated sections. There is a glossary at the end of the book, but it is incomplete and partly confused.

Specialist readers, on the other hand, will

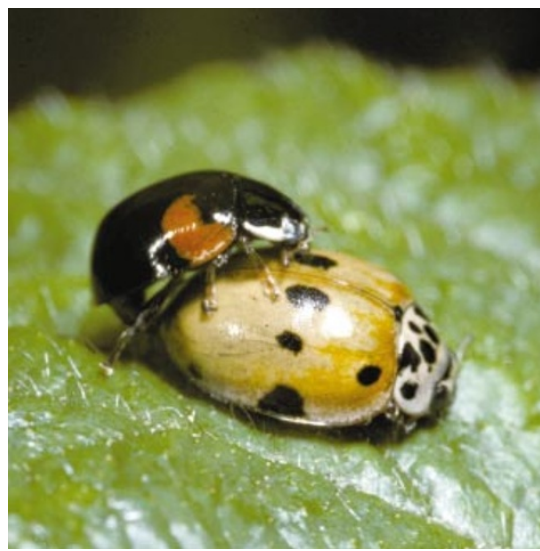

Sex to die for: females of the ladybird Adalia 10-punctata distort the sex ratio by killing males.

find the lack of reference to many case studies and ideas, as well as some more technical problems, quite annoying at times. They might also find that the book loses the battle with a more exhaustive book on sex ratios Sex Ratios, edited by I. C. W. Hardy (Cambridge University Press, 2002) - that recently reached the bookshelves. If Sex Wars were less technical and more 'popular', it might have found more enthusiastic readers.

Göran Arnqvist is in the Department of Animal

Ecology, Evolutionary Biology Centre,

University of Uppsala, Norbyvägen 18d,

SE-752 36 Uppsala, Sweden.

\section{The next happy pill}

\section{Better Than Prozac: Creating the} New Generation of Psychiatric

\section{Drugs}

by Samuel Barondes

Oxford University Press: 2003. 240 pp.

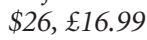

\section{Les Iversen}

The past 50 years have seen a transformation in the practice of psychiatry. The emphasis has moved from psychotherapy with a limited repertoire of drugs that were used only in the most severely ill patients, to the widespread use of drugs that act on the central nervous system (CNS), with psychotherapy being an expensive luxury for a minority of patients. Samuel Barondes is well placed to review the psychopharmacology revolution and to offer predictions for the future, as he has worked through this period as a practising psychiatrist and as an active researcher who has made important contributions to the field.

An early section of the book explains how the existing drugs used to treat psychiatric illnesses — antidepressants, antipsychotic drugs, tranquillizers and amphetamines were discovered, with colourful accounts of the individuals involved. Along the way there

\section{New in paperback}

Mapping Human History: Genes, Race, and Our Common Origins

by Steve Olson

Mariner, \$14; Bloomsbury, £7.99

Our Posthuman Future: Consequences of the Biotechnology Revolution by Francis Fukuyama

Profile, £8.99

The Golden Ratio: The Story of Phi, The Extraordinary Number of Nature, Art and Beauty

by Mario Livio

Review (Headline), £7.99

Nexus: Small Worlds and the Groundbreaking Theory of Networks by Mark Buchanan

W. W. Norton, $\$ 14.95$

"Mark Buchanan gives a cogent and engaging description of recent developments in complex networks." Sidney Redner Nature 418, 127-128 (2002).

The Monkey in the Mirror: Essays on the Science of What Makes Us Human by lan Tattersall

Harvest Books, £13

are explanations in simple language of how the drugs affect various neurotransmitter mechanisms in the brain, and an introduction to the concepts of controlled clinical trials, the placebo effect and the mystery of why it takes many weeks of treatment before the maximum therapeutic benefits of many CNS drugs are seen.

Barondes uses individual case histories to illustrate many of these points, a device that helps to involve the reader with real people who have benefited from drug treatments, and to illustrate some of the shortcomings of the medicines that are presently available. There is a graphic description, for example, of the power of the selective serotonin re-uptake inhibitor (SSRI) Prozac to transform a patient from a state of sadness and agitation to one of calm and tranquility, albeit with a diminished intellectual passion and reduced sex drive.

A second section provides an overview of the prospect that a better Prozac will emerge from current research in this field. Like many others, the author believes that this will come from a better understanding of the nature of the biological disturbances that underlie psychiatric illnesses. There is reason for optimism: several valuable clues have already emerged from research on the genetic risk factors underlying these illnesses, and potential candidate genes have been 
described in the past year for schizophrenia and for manic-depressive illness. It is likely that most psychiatric illnesses are partly inherited through genetic risk factors but also depend on environmental factors. Nevertheless, identifying the genetic risk factors may provide important clues about new treatment strategies.

A case in point is Alzheimer's disease, in which mutations in several different genes are known to increase the risk of developing the disease, and in a small number of patients, mutations in the amyloid precursor protein (APP) cause the illness directly. This new genetic information has greatly strengthened the hypothesis that the abnormal formation and deposition of amyloid- $\beta$, a protein derived from APP, is a key event underlying the pathology of Alzheimer's. This in turn has triggered a large research effort directed towards the discovery of drugs that can reduce the formation or deposition of amyloid- $\beta$. Whether these will prove effective in the clinic remains to be seen, but for the first time a rational approach to the treatment of this devastating illness has become possible.

Understanding the underlying disease process and developing medicines that interrupt this process remain the ultimate goals in devising a better Prozac. In the meantime, better drugs can be developed to treat the symptoms of psychiatric illnesses, for example by the introduction of antagonists of the neuropeptide substance $P$ to create new antidepressants that lack the adverse effects of SSRIs on sexual function. Alternatively, antagonists of the neuropeptide corticotropin-releasing factor could be used to make potential 'anti-stress' agents. New uses are also being found for existing drugs — for example, SSRIs can be used in the treatment of bulimia nervosa, obsessive-compulsive disorder, panic disorder and post-traumatic stress syndrome. The latest addition is the treatment of 'social phobia' using the SSRI paroxetine (ad line: "How shy is too shy?").

Overall, this is a well-written and comprehensive account of a field that has developed rapidly in the past few decades. It was written for intelligent non-scientific readers, but experts will also find much entertaining material about the scientists who were involved in some of the major discoveries, and in the case histories. An extensive bibliography allows access to the basic scientific literature. The development of psychopharmacology has been well reviewed by David Healy in his two books published by Harvard University Press - The Antidepressant Era (1998) and The Creation of Psychopharmacology (2002) — but Barondes' new book provides a shorter and more personal account, and is an excellent read.

Les Iversen is in the Department of Pharmacology,

University of Oxford, Mansfield Road,

Oxford OX1 3QT, UK.
Science in culture

\section{Taking it on trust}

\section{Seeing and believing the aerial photographs of Iraq.}

\section{Martin Kemp}

Ever since the earliest use of illustration in a scientific text, we have been asked to take a great deal on trust. Whether recording data or placing us more literally as a surrogate witness to what something looks like, the author is proposing a contract with the reader. When an accomplished illustrator - and no one was more accomplished than Leonardo da Vinci - depicts a unicorn, we have a natural tendency to believe our eyes. Indeed, for a Renaissance spectator, a convincing unicorn was more believable than a giraffe. In our age of computer-processed images, we know that undetectable manipulation is possible, but our perceptual system is designed to collaborate with something that looks real.

Modern science has generated a body of images of the unseeable, rather than the unseen. They demand that we trust the technological means of generation and accept the interanalysers. The showing of $X$ rays to patients is a case in point. When a women is shown a scan of her breast, and the surgeon points to the ominous patch, she is expected to see that "there is something there", and follow the doctor as he or she indicates that the lump is benign or malignant.

The aerial 'intelligence' photographs of Iraq used by Colin Powell at the United Nations, and subsequently published in a dossier by the British government, fall very much into this category of technological images that depend on expert intervention to transform seeing into believing.

What is captioned in the British dossier as "A photograph of a 'presidential site' or what have been called 'palaces'” provides a typical example (above). A hazy aerial view shows a grey patchwork of roads, railways, plots of land and buildings. The key points have been enhanced in black to define the boundary of the site and the complexes of buildings. To give a sense of scale, a white insert provides dramatic comparison with the "total area taken by Buckingham Palace and its grounds". Presumably a comparably scaled plan of the much larger Windsor Castle, complete with its Great Park and assorted buildings, would not have done the job as well.

The nature of the image, which we implicitly know to have been garnered through the most advanced means available, invites us to take it pretative framework of expert as providing concrete evidence of what was happening in Iraq. 'Evidence' was an extremely heavily used word in the debates leading up to the invasion of Iraq and in the aftermath of the conquest. The models of 'information' (another widely used term) and of 'proof' used in the public debates have been derived almost exclusively from the style and terminology of modern science and technology. We are asked to rely on

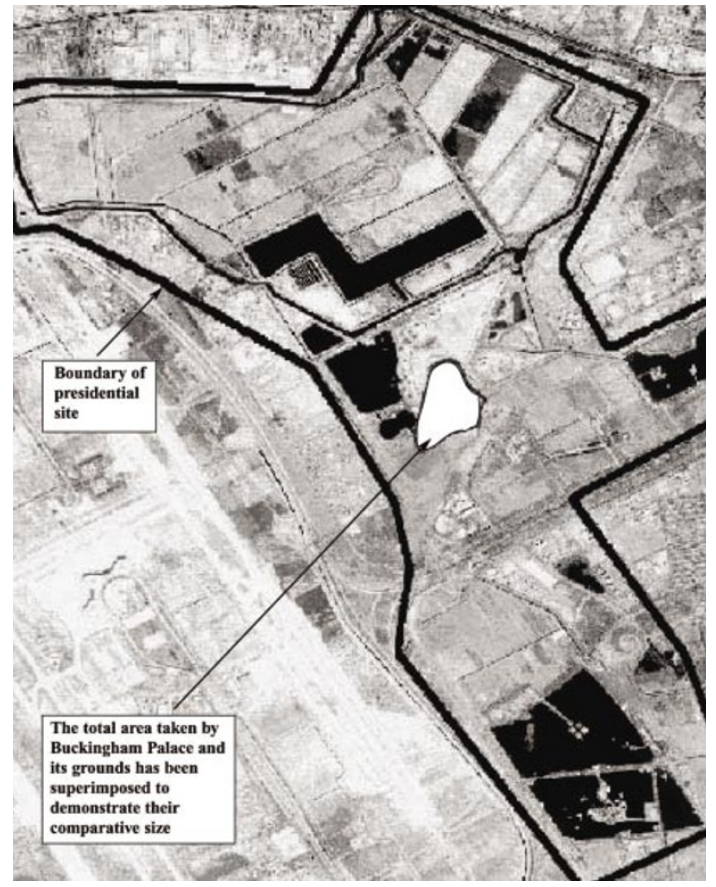

the expert interpretation of such images provided by the intelligence services to the leaders who make the fateful decisions.

Those of us who use visual evidence in academic research should not automatically feel superior to politicians. When, as a sometime art historian, I draw my students into looking at something my way, I am setting up a contract of trust. I used to demonstrate to my senior students that a drawing by Michelangelo was 'obviously' a forgery - even though it was in fact an authentic drawing with an immaculate history.

Scientists who draw clarifying outlines on indistinct pictures, insert meaningful arrows on technologically generated images, or produce line transcriptions of salient features, are asking readers to believe not only that they are honest but also that their expertise really does allow them to see something on behalf of those not endowed with such insight. It is a burden of responsibility that we would do well to remember. Martin Kemp is professor of the history of art at the University of Oxford and co-director of Wallace Kemp/Artakt. 